\title{
Short term heart rate variability in subjects with diabetes mellitus in preoperative period
}

\author{
Meldijana Omerbegović* \\ University Clinical Centre \\ Sarajevo, Sarajevo, Bosnia and \\ Herzegovina
}

KEYWORDS: cardiac autonomic neuropathy, heart rate variability, diabetes mellitus, preoperative period, prognostic factors

CITATION: Cardiol Croat. 2014;9(9-10):390.

*ADDRESS FOR CORRESPONDENCE: Klinički centar Univerziteta u Sarajevu, Bolnička 25, 71000 Sarajevo, Bosnia and Herzegovina. / Phone: +387-33-521626 / E-mail: meldi@bih.net.ba

||||||||||||||||||||||||||||||||||||||||||||||||||||||||||||||||||||||||||||||||||||||||||||||||||||||||||||||||||||||||||||

Subjects with diabetes mellitus have higher cardiovascular morbidity and mortality in perioperative period regardless of the surgical procedure and meticulous preparations for the perioperative period. It has been shown that certain number of patients with diabetes mellitus could develop cardiac autonomic neuropathy over different time periods and this would make them prone to increased haemodynamic variations during the surgical procedure, anaesthesia and the postoperative period. The alterations of the heart rate variability in subjects with diabetes mellitus have shown important clinical relevance in uncovering cardiac autonomic neuropathy before the development of serious complications of the disordered glucose metabolism. Preoperative assessment of heart rate variability could have a predictive value in differentiating between the patients with mild changes of the autonomic nervous system tone and those with severe autonomic nervous dysfunction. It could also help in predicting the haemodynamic instability and higher incidence of cardiac arrhythmias and mortality in the patients undergoing an elective surgical procedure. Determination of baseline heart rate variability in preoperative period could be important for possible individual tailoring of the procedures and the later follow up, assuring a higher sensitivity for detection of the possible complications during the convalescence period. Some of the linear and nonlinear measures of the heart rate variability calculated from the short term recordings in subjects with diabetes mellitus scheduled for an elective surgical procedures are described in this paper
RECEIVED:

September 21, 2014

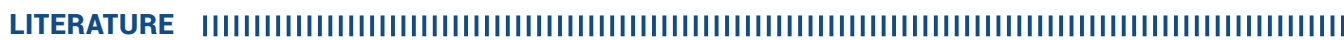

1. Vinik Al, Ziegler D. Diabetic cardiovascular autonomic neuropathy. Circulation. 2007;115:387-97.

2. Laitio T, Jalonen J, Kuusela T, Scheinin H. The role of heart rate variability in risk stratification for adverse postoperative cardiac events. Anesth Analg. 2007;105(6):1548-60.

3. Ziegler D. Cardiovascular autonomic neuropathy: clinical manifestations and measurement. Diabet Rev. 1999; 7:342-57. 